that were apoptotic was significantly higher than for normal $(32 \%$, $\mathrm{n}=8$ ), and not further increased by BzATP. o-ATP reduced the spontaneous IL- $1 \beta$ release in IBD samples.

Conclusions: Expression and functional data support the presence of $\mathrm{P}_{2} \mathrm{X}_{7}$ receptor on colonic mucosal macrophages and $\mathrm{T}$ lymphocytes. This may play a role in the immunopathology of inflammatory bowel diseases.

\section{Small Bowel Posters: 288-307}

\section{IGA ANTIBODY TO TISSUE TRANSGLUTAMINASE IS A HIGHLY SENSITIVE PREDICTOR OF ADULT ONSET COELIAC DISEASE IN CLINICAL PRACTICE}

M. Whyte, S. Smale, P.M. Heil, P. Prasad, T. Davis, C. Sewell, I. Forgacs, I. Bjarnason, H.E. Mulcahy. Dept of Gastroenterology, King's College Hospital, Denmark Hill, London SE5 9RS, UK

Introduction: Anti-endomysial antibodies have high specificity $(90 \%)$ for the presence of coeliac disease, but there are ethical and cost issues associated with using monkey oesophagus for clinical tests. Tissue transglutaminase (tTG) is the main autoantigen recognised by endomysial antibodies and commercial tests have recently become available to measure tTG in serum.

Aim: To establish the diagnostic sensitivity, specificity, positive and negative predictive value of IgA anti-tTG in adult clinical practice.

Methods: The study comprised 48 patients (mean age 52 years: range 20-86, 31 females) undergoing investigation for possible coeliac disease i. Patients with known coeliac disease were excluded from study. Serum IgA anti-tTG antibody titres were measured quantitatively by an enzyme-linked immunosorbent assay (QuantaLite tTG, Inova Diagnostics, Ca, USA). Samples were classified as negative ( $<20$ units), weakly positive $(20-30)$ or moderate to strongly positive (>30 units).

Results: Duodenal biopsies were normal in 40 patients and untreated coeliac disease was diagnosed in the remaining 8 cases. All 8 patients with coeliac disease had moderate to strongly positive antitTG antibody titres. In addition, 9 of 40 patients without coeliac disease were anti-tTG antibody titre positive ( 5 weakly positive, 4 moderate to strongly positive). Overall, IgA antitissue tTG had a diagnostic sensitivity, specificity, positive and negative predictive value of $100 \%, 78 \%, 47 \%$ and $100 \%$ respectively.

Conclusion: IgA antibody to tissue transglutaminase appears to be a highly sensitive predictor of adult onset coeliac disease in clinical practice. practice. The relatively high false positive rates for tTG in this material requires further study.

\section{IS A RAISED INTRAEPITHELIAL COUNT WITH NORMAL VILLOUS ARCHITECTURE CLINICALLY SIGNIFICANT?}

S. Mahadeva, J.I. Wyatt, P.D. Howdle. Depts of Medicine E Pathology, St fames's University Hospital, Leeds, UK

The significance of an increase in intraepithelial lymphocytes (IEL) within an otherwise normal duodenal biopsy remains uncertain. Although it may represent latent coeliac disease, there is very little information available about cases that do not have gluten-sensitive enteropathy.

Methods: A consecutive series of routine endoscopic duodenal biopsies from August'98-July'99 reported by a single pathologist was collected to assess the incidence of such a finding. Clinical details and indications for biopsy were examined in all patients. Those biopsies initially reported to have subjectively increased IELs with normal villi, together with a control group reported as normal, were reassessed by the pathologist blinded to the original report. IEL counts in the study group were compared to controls.

Results: Of 625 patients biopsied in the 12 month period, 507 were reported as normal, 104 had a specific duodenal pathology and $14(2.2 \%)$ had increased IEL with normal villi. The ages, sex ratio and clinical indications for biopsy were similar in the latter 14 when compared to the 507 patients with a normal biopsy. Enumeration of the IEL/ 100 epithelial cells confirmed an increase in all 14 patients (range 26-46/100). In the normal control group, the mean was 12.4, giving an upper limit of normal as 21.5 (mean $+2 \mathrm{SD}$ ). Of these 14,3 were positive for coeliac antibodies. The other diagnoses included chronic liver disease (3), colonic tumours (2; 1 benign, 1 malignant), irritable bowel syndrome (2), chronic pancreatitis (1) and unexplained iron deficiency anaemia (3).

Conclusions: A raised IEL count with normal villi is not uncommon $(2.2 \%)$. There is still no clear explanation for its finding in many patients. As it may represent latent coeliac disease, long term follow up studies are required, especially in those with positive coeliac antibodies.

\section{COELIAC DISEASE: EVIDENCE OF ADDITIONAL SUSCEPTIBILITY WHEN THE SECOND HAPLOTYPE IS A DR7 DQ2.1 OR A DR3 DQ2.2 IN DR3 DQ2.2 POSITIVE} SUBJECTS

S.J. Moodie, A.L. King, J.Y. Yiannakou, J.S. Fraser, E. Kondeatis, R. Vaughan, P.J. Ciclitira. The Rayne Institute, King's College, London SE1 7EH, $U K$

Introduction: $90 \%$ of UK coeliac patients carry at least one DR3 DQA $1{ }^{\star} 0501$ DQB ${ }^{\star} 0201$ (DQ2.2) haplotype. Patients without this haplotype nearly always carry either a DR4 DQ8 or encode the DQA $1{ }^{\star} 0501$ DQB $1{ }^{\star} 0201$ heterodimer in trans on DR5 and DR7 haplotypes. There is some evidence that in patients with a DR3 DQ2.2 haplotype increased susceptibility is conferred by the second haplotype being either a DR7 DQA ${ }^{\star} 0201 \mathrm{DQB} 1^{\star} 0202(\mathrm{DQ} 2.1)$ or a DR3 DQ2.2.

Aims: To assess whether a DR7 DQ2.1 haplotype conveys additional coeliac disease susceptibility in subjects with one DR3 DQ2.2 haplotype, and to compare this susceptibility to DR3 DQ2.2 homozygotes.

Methods: HLA haplotypes were determined in 58 family pedigrees each containing at least 2 coeliac patients. A PCR-SSP method was used to type for DR7, DR3, DQA ${ }^{\star} 0201$, DQA $1{ }^{\star} 0501$, $\mathrm{DQB} 1{ }^{\star} 02$ in 37 families, with 21 families only having typing for DQA 1 and DQB1. In these 21 families two microsatellites, and in 29 families 1 flanking microsatellite flanking the HLA region were assessed following PCR using ABI 373 and 377 sequencers.

Results: 42 coeliac patients were identified where, having inherited a DR3 DQ2.2 from one parent, the other parent was heterozygous for DR7 DQ2.1 (in some families more than one coeliac patient was used). In 28 of these 42 cases the DR7 DQ2.1 haplotype was transmitted to the patient ( $\mathrm{p}<0.05, \mathrm{McNemars}$ test, Yates correction) demonstrating an additive effect of this haplotype on coeliac disease risk in DR3 DQ2.2 positive patients. In 18 of these cases the other parent was heterozygous for DR7 DQ2.1 with DR3 DQ2.2. In 11 of these 18 cases the DR7 haplotype was transmitted to the patient ( $\mathrm{p}=\mathrm{NS}$ ). Compared to DR3 DQ2.2 negative subjects, the haplotype relative risk for DR3/DR3 homozygotes, DR3/DR7 heterozygotes and DR3 $/ x^{\star}$ heterozygotes were $36.1,35,10.7$ respectively. ( ${ }^{\star}$ where $\mathrm{x}$ is not DR3 or DR7).

Conclusion: A DR7 DQ2.1 haplotype conveys additional risk for coeliac disease in DR3 DQ2.2 positive patients. This additional risk was no greater than for DR3 DQ2.2 homozygotes consistent with the additional effect of a DR7 DQ2.1 haplotype being a dosage effect of $\mathrm{DQB} 1{ }^{\star} 02$.

\section{FOLLOW-UP LINKAGE STUDY OF COELIAC DISEASE: FURTHER EVIDENCE FOR THE EXISTENCE OF A SUSCEPTIBILITY LOCUS ON CHROMOSOME 11p11}

A.L. King ${ }^{1}$, J.S. Fraser ${ }^{1}$, S.J. Moodie ${ }^{1}$, D. Curtis ${ }^{2}$, A.M. Dearlove ${ }^{3}$, H.J. Ellis ${ }^{1}$, S. Rosen-Bronson ${ }^{4}$, P.J. Ciclitira ${ }^{1}{ }^{1}$ Gastroenterology Unit (GKT), The Rayne Institute, St Thomas' Hospital, London; ${ }^{2}$ Acadeic Dept of Psychological Medicine, St Bartholomew's and the Royal London School of Medicine E Dentistry, Alexandra Wing, Turner Street, London; ${ }^{3} H G M P$ Resources Centre, Hinxton, Cambridge; ${ }^{4}$ Georgetown University Medical Centre, Washington DC 20007, USA

The susceptibility to coeliac disease has a strong genetic component, as demonstrated by a $10 \%$ disease risk in first degree relatives, $30-50 \%$ concordance in HLA identical siblings, and a $70-100 \%$ concordance in monozygotic twins. The contribution of the HLA region to this genetic component has been well described but it is clear that loci outside this region must also contribute to susceptibility. Two previous genome wide linkage studies using the affected sib pair 
method have produced conflicting results. Our own family based linkage study of 16 highly informative pedigrees identified 17 possibly linked regions, each of which produced a result significant at $\mathrm{p}<0.05$ or less. We have now investigated these 17 regions in a larger set of pedigrees using more finely spaced markers. A total of 50 multiply affected families were studied, comprising the 16 pedigrees from the original genome screen plus 34 new highly informative pedigrees. A total of 128 microsatellite markers were genotyped with an average spacing between markers of $5 \mathrm{cM}$. Two point and three point linkage analysis using classical and model free methods identified five potential susceptibility loci with heterogeneity lod scores $>2.0$, at $6 \mathrm{p} 12$, $11 \mathrm{p} 11,17 \mathrm{q} 12,18 \mathrm{q} 23$, and $22 \mathrm{q} 13.3$. The most significant was a heterogeneity lod of 2.65 at D11S914 on chromosome $11 \mathrm{p} 11$. This marker maps to a position implicated in one of the two previous genome scans and taken together these results provide strong support for the existence of a susceptibility locus in this region.

\section{THE EVALUATION OF A TWO STAGE TISSUE TRANSGLUTAMINASE AND ANTIENDOMYSIAL ANTIBODY TEST AS A SCREENING TOOL FOR COELIAC DISEASE IN HIGH RISK POPULATIONS}

K. Sundaram ${ }^{1}$, G. Hayman 2 , T. Crusz ${ }^{3}$, A. Bansal ${ }^{2}$, C.G. Beckett. ${ }^{1}$ Gastroenterology Dept, Mayday Hospital; ${ }^{2}$ Immunology Dept, St Helier's Hospital; ${ }^{3}$ SE National Blood Service; Gastroenterology Dept, Bradford Royal Infirmary, UK

Introduction: Coeliac disease (CD) remains an underdiagnosed condition. It commonly presents with anaemia. The antiendomysial antibody (AEA) test is a highly sensitive and specific test for coeliac disease, but the method and cost often precludes its use as a tool to screen large populations. The discovery that tissue transglutaminase (tTG) is the antigen recognised by AEA and the development of a convenient tTG ELISA suggests that it may be used as a tool for screening for $\mathrm{CD}$.

Aims: To evaluate the role of a two step protocol employing tTG ELISA and AEA to screen for CD in two high-risk patient groups. 1. Clients who had been refused at blood donation due to anaemia. 2 . Patients attending all out-patients in whom serum ferritin was requested and found to be low.

Methods: Anonymous blood samples (EDTA) were collected by a Regional Blood Transfusion service (BTS) as a routine on individuals found to be anaemic on finger-prick testing. These samples were centrifuged on the same day and the plasma decanted. All samples with a haemoglobin less than $12 \mathrm{~g} / \mathrm{dl}$ were analysed. Anonymous serum samples were obtained from the Haematology laboratory of patients with a low ferritin $(\mathrm{f}:<6 \mathrm{ng} / \mathrm{ml}, \mathrm{m}:<16 \mathrm{ng} / \mathrm{ml}$ ). Samples were also collected from patients with normal ferritin levels as a control group. Samples were analysed using an in-house IgA anti-tTG ELISA. All anti-tTG +ve samples were subsequently tested for antiendomysial antibody status, employing indirect immunoflouresence with monkey oesophagus as substrate.

Results: Of 484 samples tested from the BTS, 8 (1:60) were tTG +ve (f:7, m:1) and of these $4(1: 121)$ were EMA +ve(f:3, m:1). Of the 166 patients with a low ferritin, 18 (1:9) were tTG +ve (f:13, m:5) and $10(1: 17)$ of these were AEA +ve), whereas 9 of 136 normal ferritins were tTG +ve $(1: 15)$ but only one was AEA +ve $(1: 136)$.

Conclusions: A high number of patients with positive serology consistent with $\mathrm{CD}$ has been found in anonymous testing of patients with a low ferritin, and to a lesser extent anaemic blood donors, in a secondary care setting. The two stage tTG ELISA and AEA regimen is a practical screening tool for CD in high risk groups. The validity of testing on EDTA samples needs to be confirmed.

\section{A STUDY OF THE USE OF ANTI-ENDOMYSIAL ANTIBODIES AND DUODENAL BIOPSIES IN A LARGE DISTRICT GENERAL HOSPITAL}

C.B. Pearce, D. Sinclair, H.D. Duncan, M. Saas, P.M. Goggin, D. Poller. Queen Alexandra Hospital, Portsmouth, UK

Background: The recent BSG guidelines for investigation of iron-deficiency suggest that duodenal biopsies (DDB's) should be taken in all patients presenting with iron deficiency anaemia (Gut 2000;46(suppl IV)), while a recent article addressing the pathology manpower crisis suggests that antibody tests could be used in place of DDB's to free pathologists to address Government cancer guidelines (Quirke P. Hospital Doctor 28 Sept 2000).
Aim: To evaluate the results of anti-endomysial antibodies (EMA) and DDB in Portsmouth hospitals from Apr ' 99 to Sept '00 and the need for investigation of other methods of diagnosis of coeliac disease (CD).

Method: The records of all patients were examined from whom DDB's were taken between Apr ' 99 and Sept '00 and that had EMA tested between Dec '99 and Sept '00. 1450 EMA and 361 DDB results were examined. Patients and their GP's who were EMA +ve but had no DDB and patients with false -ve EMA were contacted.

Results: Of the 361 DDB's 108 patients had 113 EMA's. 44 patients had +ve DDB's and of these 25 had a +ve EMA. 8 patients had a DDB that was felt to be diagnostic of CD but had a -ve EMA. 2 of these had IgA deficiency, but only one was IgG EMA +ve. 4 of the EMA tests were done after the DDB, and were performed on a gluten-free diet. We therefore found 4 true false -ve IgA EMA tests and 3 true false -ve EMA tests after IgA levels and IgG EMA (sensitivity $=86 \%$, specificity $=100 \%(\mathrm{p}<0.0001))$. On follow-up one has been found to have a T-cell lymphoma. Of the 1450 EMA tests only 35 had a DDB and of the 67 +ve EMA tests 55 had no DDB.

Comment: The low sensitivity of EMA and the low take-up of DDB in patients who had EMA test gives rise to a worry that patients with $\mathrm{CD}$ are being missed and are at risk from the morbidity of untreated CD.

Future direction: DDB should be further evaluated as an investigational tool. Tissue transglutaminase should be evaluated as a method of investigating CD. The differential diagnosis of patients with histological features of CD should be considered in EMA +ve patients.

\section{DOES ANTI-ENDOMYSIAL ANTIBODY SEROCONVERSION PREDICT HISTOLOGICAL RECOVERY IN COELIAC DISEASE?}

\section{S.M. Kelly. York District Hospital, Wigginton Rd, York, UK}

Objective: IgA anti-endomysial anibody (AEA) is highly sensitive and specific for coeliac disease and is a useful screening tool. There is some evidence to suggest that it can be used to assess dietary compliance, but its exact value in follow up of patients remains unclear. Of particular interest is whether seroconversion predicts mucosal response to a gluten free diet.

Method: To assess this issue we retrospectively reviewed the results of a total of 46 patients with coeliac disease. Data on both histology and aea status at initial diagnosis and subsequent follow up were obtained.

Results: A total of 24 patients had complete paired data. 22 patients (average age $47.6 \mathrm{yrs}, 9$ female) seronconverted to a negative AEA . All had a normal repeat duodenal biopsy or a substantial improvement to near normal histology (average biopsy interval 9.6 months). In 2 patients the AEA remained positive and repeat duodenal biopsies revealed persisting villous atrophy with no change from the initial biopsy (average biopsy interval 8 months).

Conclusion: In this small study there was good correlation between seroconversion and mucosal response. To make a firm diagnosis of coeliac disease one does need to see a histological response to gluten withdrawl. However some patients decline to have a second biopsy and in this case many clinicians would be happy with the diagnosis if there is a good clinical response to gluten free diet and AEA seroconversion. In this study a follow-up positive AEA predicted persisting villous atrophy and seroconversion a good mucosal response. Therefore although a repeat duodenal biopsy remains the "Gold Standard" AEA status does appear to give a very good guide to mucosal response.

\section{TRENDS IN CLINICAL PRESENTATION OF ADULT COELIAC DISEASE: A 25 YEAR PROSPECTIVE STUDY}

J. West ${ }^{1}$, B.P. Palmer ${ }^{1}$, G.K.T. Holmes ${ }^{2}$, R.F.A. Logan ${ }^{1} .{ }^{1}$ Division of Public Health and Epidemiology, University of Nottingham, Nottingham, NG7 2UH; ${ }^{2}$ Dept of Medicine, Derbyshire Royal Infirmary, London Road, Derby DE1 2QY, $U K$

Introduction: With the advent of accurate serological tests many centres are reporting increasing numbers of coeliac disease (CD) diagnoses. This could indicate a true increase in incidence or alternatively reflect greater awareness of CD and better diagnostic tests. We have used data prospectively collected over 25 years to examine rate of diagnosis, trends in presentation and changes in severity of illness. 
Methods: All adults with CD at the 2 District General Hospitals within Southern Derbyshire (population circa 500,000) have been identified at diagnosis and prospectively followed. Data collected includes date of diagnosis, symptoms and signs at presentation and reason for investigation/diagnosis. We analysed the data over 5 quinquenia (1975-99). Routine use of antigliadin antibody and antiendomysial antibody began in 1987 and 1997 respectively.

Results: Trends in demographics, symptoms at presentation and reason for referral in 567 adult patients with $\mathrm{CD}$ are shown in the table.

Abstract 295, Table 1

\begin{tabular}{lllllll}
\hline & $\begin{array}{l}\text { Total } \\
\text { number of } \\
\text { patients }\end{array}$ & $\begin{array}{l}\text { Mean } \\
\text { age at } \\
\text { diagnosis }\end{array}$ & Female & Diarrhoea & $\begin{array}{l}\text { Nonel } \\
\text { non-specific }\end{array}$ & $\begin{array}{l}\text { Incidental } \\
\text { anamia }\end{array}$ \\
\hline $75-79$ & 35 & 41 & $25(71)$ & $25(71)$ & $3(9)$ & $1(3)$ \\
$80-84$ & 55 & 44 & $34(62)$ & $33(60)$ & $5(9)$ & $4(7)$ \\
$85-89$ & 70 & 47 & $47(67)$ & $45(64)$ & $10(14)$ & $1(1)$ \\
$90-94$ & 141 & 50 & $108(77)$ & $64(45)$ & $22(16)$ & $19(14)$ \\
$95-99$ & 266 & 51 & $180(68)$ & $97(37)$ & $56(21)$ & $44(17)$ \\
Total & 567 & 49 & $394(70)$ & $264(47)$ & $96(17)$ & $69(12)$ \\
\hline
\end{tabular}

Conclusions: We found a rapidly increasing rate of diagnosis of $\mathrm{CD}$, accelerated with the introduction of accurate serological tests. Severity of illness appears to have declined. These results are explicable in terms of greater awareness and improved diagnostic methods rather than a true increase in incidence, consistent with the concept of the CD "iceberg" being revealed.

\section{DOES SERUM IGA ANTI-TTG ANTIBODY CONCENTRATIONS REFLECT SEVERITY OF MUCOSAL DAMAGE IN UNTREATED COELIAC DISEASE?}

A. Dahele, Q. Liang, J. Bode, S. Ghosh. GI Laboratory, Dept of Medical Sciences, Western General Hospital, Edinburgh, UK

Introduction: The contribution of IgA anti-tTG antibodies to the pathogenesis of mucosal damage in coeliac disease is controversial. It has been suggested that anti-tTG antibodies interfere with cellular differentiation and may result in mucosal flattening. TTG has been shown to be important in wound healing and anti-tTG antibodies might prevent restitution of mucosal integrity after injury. On the other hand coeliac disease is common in selective IgA deficiency, casting doubt on any pivotal pathogenetic role of IgA anti-tTG antibodies.

Patients and methods: Fifty three prospectively diagnosed, untreated coeliac disease patients were included in this study. IgA anti-tTG antibody ELISA was developed in-house using tTG from guinea pig liver (Sigma). Upper reference limit 2950 units/mL. All biopsies were graded 0-4 using the Marsh criteria. Sugar permeability test was performed $(n=48)$ using differential lactulose/ rhamnose sugar absorption. Intraepithelial (IEL) $\mathrm{CD}^{+}$and $\gamma / \delta$ TCR were counted by immunocytochemistry using anti-CD 3 and anti- $\gamma / \delta$ antibodies on cryostat sections and using image analysis. Micro-dissection of duodenal biopsies placed in Clarke's fixative followed by IMS99 was carried out to quantitate crypt depth $(n=26)$, villous height $(n=20)$ and the number of mitoses/crypt $(n=24)$.

Results: $14 / 22$ (64\%) patients with Marsh grade $1 \& 2$ compared with $21 / 31(68 \%)$ with Marsh grades $3 \& 4$ had serum IgA anti-tTG concentrations above 2950 units $/ \mathrm{ml}\left(\chi^{2}=0.1 ; \mathrm{p}=\mathrm{ns}\right)$. The IEL count did not correlate with serum IgA anti-tTG concentration $\left(r^{2}=0.02 ; p=n s\right)$. Epithelial CD 3 and $\gamma / \delta \mathrm{T}$ cell counts did not correlate with $\operatorname{IgA}$ anti-tTG concentrations $\left(\mathrm{r}^{2}=0.007 ; \mathrm{p}=\mathrm{ns} \& \mathrm{r}^{2}=0.14 ; \mathrm{p}=\mathrm{ns}\right)$. There was no correlation between sugar permeability (lactulose/ rhamnose ratio) and serum IgA anti-tTG antibody concentrations $\left(r^{2}=0.0009 ; p=n s\right)$. Crypt depth positively correlated but very weakly with IgA anti-tTG antibody concentration $\left(\mathrm{r}^{2}=0.2 ; \mathrm{p}<0.02\right)$. However, villous length or number of crypt mitoses showed no significant correlation with IgA anti-tTG antibody concentration $\left(r^{2}=0.16 ; p=0.08 \& r^{2}=0.0001 ; p=n s\right)$.

Conclusion: There was no significant association between Marsh grade, IEL, CD 3 or $\gamma / \delta$ TCR counts, micro-dissection parameters or Lactulose/Rhamnose ratio and anti-tTG antibody concentrations in the serum. Serum IgA anti-tTG antibody is unlikely to be directly responsible for causing mucosal lesions in untreated coeliac disease.
297 IS REFRACTORY COELIAC DISEASE AN ADULT FORM OF AUTOIMMUNE ENTEROPATHY?

C.A. Rodrigues', R. Mirakian², M. Shattock², M. Helbert², P.J. Kumar'. Depts of Adult and Paediatric Gastroenterology $y^{1}$ and Immunology', St Bartholomew's and the Royal London School of Medicine and Dentistry, London, UK

Enterocyte antibody (ECA) is the marker for autoimmune enteropathy in children. To date such an enteropathy has not been described in adults but ECA has been reported in 3 adult patients with refractory coeliac disease (CD) worldwide. We tested sera of 8 patients with refractory CD ( $7 \mathrm{~F}$; median age 60 yrs, range 44-77; 2 with ulcerative jejunitis) for the presence of ECA. 10 patients with CD responsive to a gluten free diet (7 F; 24 [18-69]), 9 patients with irritable bowel syndrome (IBS) (6 F; 37 [19-47] and 5 healthy young adults (1 F) were also studied as controls. In the refractory group IgA endomysial antibody was present in 3 of 6 patients tested, antigliadin antibody in 3 of 7 patients and antireticulin antibody in 4 of 8 . Antinuclear antibody was detected in 5 out of 8 patients with refractory disease, smooth muscle antibody in 4, antimitochondrial antibody (AMA) in 1 and thyroid microsomal antibody in 1 .

Sera were tested on 3 separate blood group $\mathrm{O}$ human duodenal cryostat sections using immunofluorescence. Serum from a child with autoimmune enteropathy was used as a positive control. Sera containing AMA and liver/kidney microsomal antibodies were also tested as they stain the enterocyte cytoplasm with a different pattern to that seen for ECA.

No classical ECA pattern was detected in any of the refractory coeliac patients. ECA was not detected in healthy controls, in IBS patients and was not present in 9 responsive coeliac patients. 1 patient in the latter group, who was untreated at the time the serum sample was collected, had patchy weak positive reactivity within the mature enterocyte cytoplasm. These results suggest that patients with refractory coeliac disease do not have an adult form of autoimmune enteropathy.

\section{COELIAC DISEASE IN SOUTH ASIANS RESIDENT IN BRITAIN: COMPARISON WITH WHITE CAUCASIANS}

J.R. Butterworth, T.H. Iqbal, B.T. Cooper. Gastroenterology Unit, City Hospital, Birmingham $\mathrm{B} 18 \mathrm{7QH}, \mathrm{UK}$

Background: The catchment population of our hospital is ethnically diverse and we have seen a number of patients of South Asian origin with coeliac disease. We have suspected that there are clinical differences compared to white European coeliacs especially with respect to anaemia and vitamin $\mathrm{D}$ deficiency at presentation.

Methods: We retrospectively and prospectively reviewed the notes of patients attending the adult coeliac clinic over the last 10 years. All patients were diagnosed after the age of 16 . There were 39 South Asians (16M:23F; aged 16-55 mean 27 years) and 90 white Caucasians (38M:52F; aged 16-76 mean 46 years). Symptoms, haematology, biochemistry, endomysial antibody status and small bowel histology at presentation and follow up were compared between the two racial groups.

Results: There were significant differences between the racial groups. South Asians were younger at presentation (mean age $27 \mathrm{v} 47$ years, $\mathrm{p}<0.0001)$; they were less likely to have 'irritable bowel' syndrome (IBS) symptoms $(P<0.01)$, but more likely to have vitamin $\mathrm{D}$ deficiency $(\mathrm{P}<0.03)$. Their haemoglobin $(\mathrm{P}<0.05)$, mean cell volume $(\mathrm{MCV})(\mathrm{P}<0.0004)$, serum iron $(\mathrm{P}<0.01)$, transferrin saturation $(\mathrm{p}<0.05), 1,25$ dihydroxyvitamin D3 $(\mathrm{P}<0.002)$, and serum albumin $(\mathrm{p}<0.05)$ levels were lower, whilst serum alkaline phosphatase levels were higher $(\mathrm{P}<0.04)$ than in white European coeliac patients. There were no differences with respect to serum folate, vitamin B12, serum calcium, alanine aminotransferase (ALT) and small bowel histology. IgA class endomysial antibody positivity was the similar in the two groups (88.5\% for Asians Vs $73.5 \%$ for Europeans $(\mathrm{p}=0.153))$. South Asians were less likely to stick strictly to a gluten free diet.

Conclusion: We conclude that South Asians are less likely to present with IBS symptoms, but more likely to have features of vitamin $\mathrm{D}$ and iron deficiency, and have higher alkaline phosphatases than whites Europeans with coeliac disease. There are major education problems with regard to the gluten free diet in South Asians. 


\section{SUCCESSFUL INFLIXIMAB TREATMENT FOR STEROID REFRACTORY COELIAC DISEASE}

I.D.R. Arnott ${ }^{1}$, S. Campbell ${ }^{1}$, A. Dahele ${ }^{1}$, M. McIntyre ${ }^{2}$, S.Ghosh ${ }^{1}$ ${ }^{4}$ Gastrointestinal Unit and ${ }^{2}$ Department of Pathology, Western General Hospital, Edinburgh, UK

Introduction: Coeliac disease is a T-cell mediated enteropathy induced by gluten in genetically predisposed individuals. The majority of patients respond to gluten free diet, but a small number do not. After the exclusion of gluten in the diet, ulcerative jejunititis and an enteropathy associated T-cell lymphoma, other treatment modality such as systemic steroids and immunosuppressives may be necessary. Recent evidence has suggested that anti-TNF $\alpha$ antibodies have a role in the amelioration of an animal model of villous atrophy.

Case report: We report the case of a 47-year-old caucasian female with immunoglobulin A deficiency. She was diagnosed as coeliac disease with subtotal villous atrophy on jejunal biopsy together with positive anti-endomysial and anti-gliadin immunoglobulin $\mathrm{G}$ antibodies. Despite close adherence to a gluten free diet her weight continued to drop, she had diarrhoea, and her distal duodenal histology showed no improvement. Some improvement in her symptoms was seen with cyclosporin and systemic steroids but this was not sustained and after careful consideration she was given Infliximab. There has been a dramatic improvement in her weight, symptoms and distal duodenal histology. The response has been maintained for 4 months.

Conclusions: We conclude that Infliximab is an effective treatment that may be considered in a small number of patients with severely resistant coeliac disease.

\section{CHANGES IN BONE DENSITY IN TREATED COELIAC PATIENTS DETECTED CLINICALLY AND BY SCREENING}

R.G.P. Watson, C. Rodgers, S. Johnston, S. McMillan, M. Crone. Dept of Medicine, The Queen's University Belfast, Belfast BT12 6BA, Northern Ireland

We have previously shown that bone density (BD) is significantly reduced (with a T score $<-1$ ) in $63 \%$ of clinically diagnosed coeliacs (typical CD) and in $61 \%$ of unrecognised and relatively asymptomatic cases diagnosed in a screening programme (screened $\mathrm{CD}$ ). The aim of this study was to investigate the effect of a gluten free diet (GFD) on bone density in both types of coeliacs.

Forty one typical CD patients (31 females, mean age 48 ) and 18 screened CD patients (14 females, mean age 54 ) had bone density measured by DEXA scanner at lumbar spine and hip. After 12-18 months $\mathrm{BD}$ was repeated. Adherence and response to a GFD was assessed by anti endomysial antibody (EMA). It was negative in 30 of the typical CDs and in 12 of the screened CDs.

Results: Overall there was no significant improvement in both groups for bone density at lumbar spine or hip. There was also no improvement in the 2 groups when only patients compliant with a GFD were considered. However for patients with a starting $\mathrm{BD}<1$ who were compliant with a GFD there was a significant improvement in hip BD in the typical CD group ( $\mathrm{n}=16$; median -2.0 to $-1.95 \mathrm{p}=$ 0.043). There was also a trend to improvement in lumbar BD with normalisation to >-1 in 4 patients. For the equivalent 7 patients in the screened CD group there were no significant increases although lumbar spine BD normalised in 2 .

Conclusion: Treatment of coeliac disease with a GFD for 12-18 months does not produce a clear cut improvement in BD. Benefit was seen in some patients with a significantly low starting $\mathrm{BD}(<-1)$ but normalisation of $\mathrm{BD}$ to $>-1$ occurs in only a small number of cases. This result does not provide evidence to support widespread screening for asymptomatic coeliac disease. A longer term study is required.

\section{ENTEROCYTE DYNAMICS IN THE TISSUE-ENGINEERED INTESTINE}

A. Tavakkolizadeh, A.E. Stephen, S. Kaihara, D.L. Mooney, B.S. Kim, S.W. Ashley, J.P. Vacanti, E.E. Whang.

Introduction: Native intestine possesses a dynamic mucosa. The aim of this study was to characterise the topography of enterocyte proliferation and apoptosis in the neomucosa of the tissue-engineered intestine.
Methods: Biodegradable polymers seeded with neonatal rat intestinal organoid units were implanted in adult rats to form neointestinal cysts. Five weeks after implantation, five of the rats underwent a side-to-side cyst-jejunal anastomosis. All rats were sacrificed at 6 months. Morphology, epithelial cell proliferation (Br-dU immunohistochemistry) and apoptotic rates (TUNEL assay) were assessed for native jejunal (Jej) and non-anastomosed (N-N) and anastomosed (A-N) neointestinal tissues. Groups were compared using ANOVA.

Results: A-N neomucosa consisted of folds resembling native jejunal crypts and villi, whereas N-N neomucosa was poorly developed. The anastomosis was patent in $80 \%$ of the rats at 6 months.

Abstract 301, Table 1

\begin{tabular}{lllll}
\hline $\begin{array}{l}\text { Mucosal thickness } \\
(\mu \mathrm{m})\end{array}$ & $\begin{array}{l}\text { Muscularis } \\
\text { thickness }(\mu \mathrm{m})\end{array}$ & $\begin{array}{l}\text { Br-dU rate } \\
(\%)\end{array}$ & $\begin{array}{l}\text { Apoptic rate } \\
(\%)\end{array}$ \\
\hline Jej & $551.4 \pm 12.5$ & $117.0 \pm 5.3$ & $47.3 \pm 2.7$ & $0.87 \pm 0.23$ \\
$\mathrm{~N}-\mathrm{N}$ & $102.5 \pm 83.7^{\star}$ & $537.9 \pm 171.8^{\star}$ & $32.1 \pm 16.2$ & $0.46 \pm 0.46$ \\
$\mathrm{~A}-\mathrm{N}$ & $538.9 \pm 95.7 \dagger$ & $358.2 \pm 34.0^{\star}$ & $60.5 \pm 4.7 \dagger$ & $0.77 \pm 0.18$ \\
\hline
\end{tabular}

${ }^{\star} \mathrm{p}<0.05$ compared to Jej, $\mathrm{tp}<0.05$ compared to $\mathrm{N}-\mathrm{N}$

Neomucosal epithelial proliferation was confined to the lower third of the folds. Apoptosis was evenly distributed throughout the epithelium.

Conclusions: These results suggest that the tissue-engineered neomucosa can regenerate structural and dynamic features of the normal jejunum. Anastomosis to the native intestine is an essential step for the development of the neomucosa. Tissue engineering represents a novel approach to the treatment of patients suffering from short bowel syndrome.

\section{INTESTINAL CELL PROLIFERATION AND CRYPT BRANCHING IN PARENTERALLY AND ORALLY FED RATS, EFFECTS OF GASTRIN AND GLYCINE EXTENDED GASTRIN}

A.J. Fitzgerald, M.A. Ghatei ${ }^{1}$, N. Mandir ${ }^{2}$, S.R. Bloom ${ }^{1}$, L. Iverson ${ }^{3}$, R.A. Goodlad ${ }^{2}$. Dept of Histopathology, ${ }^{1}$ Depts of Molecular Medicine and ${ }^{3}$ Clinical Pharmacology, Imperial College School of Medicine, Hammersmith Hospital, London; ${ }^{2}$ Histopathology Unit, Imperial Cancer Research Fund, 44 Lincoln's Inn Fields, London, UK

Background and aims: The role of gastrin in the modulation of epithelial cell proliferation in normal tissues other than the stomach is still controversial. A possible explanation is that the active agent is a processing variant of gastrin, glycine extended gastrin (G17-Gly). We investigated the effects of G17-Gly on rats fed by total parenteral nutrition (TPN) and in orally fed rats.

Methods: Five sets of six TPN fed rats were infused with either 0 , 4,20 , or $100 \mu \mathrm{g} / \mathrm{rat} /$ day of G17-Gly, with a further group on 100 $\mu \mathrm{g} / \mathrm{rat} /$ day of human gastrin as a positive control. Twelve orally fed rats had subcutaneous implantation of mini-osmotic pumps containing either saline or G17-Gly. After seven days, rats were killed 2 hrs after injections of vincristine sulphate to arrest cells in metaphase. Metaphase arrest and crypt branching were studied in microdissected crypts.

Results: Gastrin produced a profound fall in gastric $\mathrm{pH}$ and an increase in the weight of the stomach and small intestine. A marked proliferative effect of gastrin was seen on the stomach and proximal small intestine, which diminished distally. No effect of gastrin was seen on proliferation in the colon. G17-Gly had little effect on gastric $\mathrm{pH}$, nor on weight or proliferation of the stomach, small intestine or colon. Neither agent affected crypt branching in the small intestine or colon. Both cell proliferation and crypt branching were very significantly decreased in the TPN groups when compared to the orally fed.

Conclusion: Gastrin is trophic to the stomach and proximal small intestine but the effects on the distal small bowel were not pronounced. No effect of gastrin on proliferation in the colon could be detected. G17-Gly is not a major mitogen for the normal intestinal epithelium. 


\section{A NOVEL EPITHELIAL CALCIUM CHANNEL AND HUMAN INTESTINAL CALCIUM ABSORPTION}

N.F. Barley, D. O'Callaghan, A. Howard, S. Legon, J.R.F. Walters. Imperial College School of Medicine, Hammersmith Campus, London W12 0NN, UK

The absorption of dietary calcium by the intestine is necessary for mineralisation of the skeleton and maintenance of bone mineral density. The fraction of calcium absorbed can vary between 10 and $60 \%$ in different individuals and is a factor in the development of osteoporotic fractures. The reasons for this individual variation are unclear. Less than half is explained by established factors such as vitamin D metabolites, PTH or dietary fat and fibre-suggesting that other mechanisms remain to be discovered. To investigate this further, we have studied the expression of a new class of apical membrane calcium channel in human duodenum.

Based on sequence data from the rabbit ECAC and rat CAT1 apical membrane calcium channels described last year, we synthesised mixed PCR primers predicted to amplify both of these. Using human duodenum cDNA, we described a CAT1 homologue, which is now named ECAC2. This was readily amplified from duodenum but using these primers, we were unable to detect the other sequence, ECAC1. Using other gene-specific primers, both ECAC2 and ECAC1 could be amplified from human kidney but only ECAC2, and not ECAC1, was amplified with these from human duodenum. The two genes have about $91 \%$ nucleotide identity in the region studied.

Expression was studied by northern blotting in a series of duodenal biopsies from 20 subjects using an ECAC2 probe. RNA expression varied considerably, with a 10 -fold range between the lowest and highest values after correction for differences in loading. There was no correlation of expression with serum 1,25-dihydroxyvitamin D, but there was a strong correlation with RNA expression for the basolateral membrane calcium-pumping ATPase, PMCA1 $(\mathrm{r}=0.83, \mathrm{p}<0.001)$ suggesting that there is regulated expression the genes for calcium entry and exit. An ECAC1 specific 3'-probe gave no signal in duodenum. These results demonstrate important differences in the level of duodenal expression of ECAC2 between individuals. This may be a major factor producing vitamin $\mathrm{D}$-independent variations in human calcium absorption.

\section{GLICENTIN, AN ACTIVE ENTEROGLUCAGON, HAS A POTENT SIGNIFICANT TROPHIC ROLE ON THE SMALL INTESTINE BUT NOT ON THE COLON}

M. Sasaki, A.J. FitzGerald, N. Mandir', K. Sasaki², N.A. Wright, R.A. Goodlad $^{1}$. Dept of Histopathology, Imperial College School of Medicine, Hammersmith Hospital, London; ${ }^{1}$ Histopathology Unit, Imperial Cancer Research Fund, London; ${ }^{2}$ Nisshin Kyorin Pharmaceutical Co. Ltd, Saitama, fapan

Background and aims: Various experiments have indicated that enteroglucagon is associated with the proliferation of small intestine. However, recent studies have failed to show trophic effects of enteroglucagon on the small intestine, and glucagon like peptide 2 has been shown to be a potent intestinal growth factor. In this study, we examined the effects of an active enteroglucagon, glicentin, on intestinal proliferation using the sensitive TPN maintained rat model.

Methods: Rats were established on TPN for 6 days. Four experimental groups were as follows; $1,4,20,80 \mu \mathrm{g} / \mathrm{rat} /$ day of glicentin given via the jugular vein. TPN fed rats and rats fed chow ad libitum were used as controls. Tissues taken from duodenum, jejunum, ileum and colon were fixed in Carnoy's fluid. These tissues were microdissected to determine the metaphase arrest scores and crypt fission ratios.

Results: Body weights and weight of the small intestine and colon were not changed by glicentin administration. The mean metaphase arrest scores per crypts of the small intestine were significantly

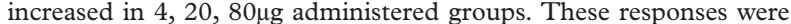

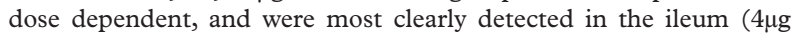
$+12.9 \% \mathrm{p}<0.05,20 \mu \mathrm{g}+25.5 \% \mathrm{p}<0.0180 \mu \mathrm{g}+35.9 \% \mathrm{p}<0.01)$. Crypt fission of the ileum was significantly decreased in $80 \mu \mathrm{g}$ glicentin group (control $7.9 \pm 1.9 \%$ vs $80 \mu \mathrm{g} 3.7 \pm 1.4 \% \mathrm{p}<0.05$ ). There were no differences in the metaphase arrest scores of the colon.

Conclusion: Glicentin has a trophic effect on the small intestine. Both enteroglucagon and glucagon like peptide 2 should be considered as growth factors for the small intestine, perhaps acting co-operatively.
305 A PLANT LECTIN FROM ROBINIA PSEUDOACACIA (ATL-101) NORMALISES INTESTINAL CRYPT CYTOKINETICS AND MORPHOMETRICS FOLLOWING TREATMENT WITH 5-FU IN A RAT MODEL*

J.M. Gee ${ }^{1}$, A.C.J. Polley ${ }^{1}$, E.K. Lund ${ }^{1}$, R.M.J. Palmer ${ }^{2}$, C. Dunk ${ }^{2}$, I.T. Johnson ${ }^{1}$. 'Institute of Food Research, Norwich Research Park, Norwich NR4 7UA; '2Alizyme Therapeutics Ltd, Granta Park, Great Abington, Cambridge CB1 6GS, UK

Background and aims: Plant lectins interact with cell membrane glycoproteins and influence the proliferation and differentiation of intestinal epithelial cells. Using a rat model, we have investigated the capacity of a lectin (ATL-101), from the bark of Robinia pseudoacacia, to attenuate the toxic effects of 5-fluorouracil (5-FU) against the intestinal mucosa.

Methods: Male Wistar rats, fed a semi-synthetic diet, received gavages of ATL-101 or saline control on days 0,1 and 2 of the experiment. Animals (5 lectin; 5 control) were killed 1, 2, 3, 4, 5 and $7 \mathrm{~d}$ after the first gavage. The small intestines were removed and weighed, and samples of proximal jejunum taken to determine crypt length, mitosis and apoptosis in whole crypt mounts. Mucosal alkaline phosphase and diacylglycerol (DAG) levels were also determined. In a second experiment, rats were gavaged with lectin or saline for 3 consecutive days prior to injection with 5-FU or saline (i.p.) on the 4 th day. Three days later animals were killed, and crypt cytokinetics were assessed as described above.

Results: Tissue hyperplasia was maximal after three doses of ATL-101. Crypt length and crypt cell mitosis peaked after two gavages, but there was no change in apoptosis. Reduced levels of alkaline phosphatase and increased intracellular DAG were seen in hyperproliferating mucosa. All measured parameters returned to pre-gavage levels 4 days after cessation of treatment. 5-FU significantly disrupted crypt cytokinetics, reducing jejunal crypt length $(\mathrm{p}<0.05)$ and mitosis $(\mathrm{p}<0.001)$. Pre-treatment with ATL-101 reduced the damage due to $5-\mathrm{FU}$, by increasing crypt cell mitosis $(\mathrm{p}<0.05)$ within the normal proliferative compartment in the lower half of the crypt.

Conclusions: Treatment with the lectin normalises crypt cytokinetics following 5-FU administration, by provoking a trophic response in the tissue, possibly mediated by a DAG-related pathway. This effect may be of benefit in the management of gastrointestinal mucositis.

\section{AN AUDIT OF THE INVESTIGATION OF IN-PATIENT DIARRHOEA IN A TEACHING HOSPITAL-TOO DIFFICULT?}

H.L. Spencer, M.T. Donnelly, K. Teahon. Nottingham City Hospital, Hucknall Rd, Nottingham NG5 1PB, UK

Introduction: Diarrhoea in hospital in-patients is common with significant morbidity, mortality and cost implications. Often the cause is not due to infection but the investigation of such patients is inconsistent and may not focus on the most likely pathogens.

Method: A prospective audit of 250 consecutive stool samples sent for microbiological investigation was carried out. Demographic data on all the patients concerned was collected. Case notes, therapy charts and patients were reviewed.

Results: 250 samples were analysed $(117 \mathrm{~m}, 137 \mathrm{f})$. Mean age of the patients was 65.3 years (range $14-94$ ). All 250 samples were tested for salmonella, shigella and campylobacter. 190 were tested for Clostridium difficile (only if requested or patient stated to be on antibiotics). Positive microbiological results were obtained in 42 samples as detailed below:

Abstract 306, Table 1

\begin{tabular}{lcc}
\hline Organism & Number of samples & \% of samples \\
\hline Campylobacter & 6 & 2.4 \\
Salmonella & 3 & 1.2 \\
Giardia & 2 & 0.8 \\
Viral (SRV, SRSV) & 2 & 0.8 \\
Clostridium difficile & $29(+2)^{\star}$ & $11.6(12.4)^{\star}$
\end{tabular}

^29 patients were positive for C.difficile toxin. In addition, 1 patient had the diagnosis made at sigmoidoscopy and 1 at post-mortem. 186 patients with a negative stool culture, had a non-infectious cause for their diarrhoea identified on clinical review; the commonest being antibiotic associated in 48 cases $(19 \%)$, laxatives in $35(14 \%)$, diet/feeding in $23(9 \%)$, post-chemotherapy in $14(6 \%)$ and constipation with overflow in $9(4 \%)$ 
Conclusions: In-patients with diarrhoea usually have a noninfectious cause for their condition. In the most of these, the cause is iatrogenic. When the cause is enteric infection, by far the commonest cause is C. difficile (not routinely tested for), with all other pathogens (routinely tested for) being very uncommon. All in-patients with hospital-acquired diarrhoea should be tested for Clostridium difficile infection routinely.

\section{ABSTRACT WITHDRAWN}

\section{Inflammatory Bowel Disease Posters: 308-339}

\section{THE EFFECT OF SULPHASALAZINE, 5-AMINOSALICYLIC ACID AND SULPHAPYRIDINE ON SULPHIDE PRODUCTION BY SULPHATE REDUCING AND AMINO ACID FERMENTING BACTERIA}

L.M. Edmond, J.H. Cummings. Dept of Molecular and Cellular Pathology, Ninewells Hospital and Medical School, Dundee, Scotland DD1 9SY, UK

Background: Reduced sulphur compounds, such as sulphide, have been implicated in ulcerative colitis (UC). ${ }^{1}$ Sulphide may be produced either from fermentation of sulphur amino acids or reduction of sulphate by sulphate reducing bacteria (SRB). In faecal slurries ASA and sulphasalazine (SAS) have been shown to reduce sulphide production from sulphate ${ }^{2}$ and from methionine.

Aims: To look at the effects of SAS, ASA and sulphapyridine (SP) in pure cultures on sulphide production from $\mathrm{SO}_{4}$ by $\mathrm{SRB}$ and sulphur amino acids by an amino acid fermenter.

Methods: An amino acid fermenter producing sulphide was isolated from a human faecal sample and provisionally identified as a fusobacterium. Desulphovibrio desulphuricans was the SRB used. The SRB was grown in Postgate $C$ in universals and the fusobacterium was grown in Wilkins Chalgren anaerobe broth with $0.5 \mathrm{~g} / 1$ cysteine and $0.5 \mathrm{~g} / 1$ methionine. Concentrations of SAS, ASA or SP from 0 to $40 \mathrm{mM}$ were added to the universals prior to autoclaving. $20 \mathrm{mM}$ ASA is considered physiological. After cooling $0.5 \mathrm{ml}$ fusobacterium or SRB stock was injected into each universal and the culture was incubated at $37^{\circ} \mathrm{C}$ for $18 \mathrm{hr}$. $1 \mathrm{ml}$ of solution was used for sulphide determination by microdistillation and HPLC.

Results: SAS achieved a $90 \%$ inhibition of sulphide production from $\mathrm{SRB}$ and fusobacterium at $1 \mathrm{mM}$ and $5 \mathrm{mM}$ respectively. ASA $90 \%$ inhibited SRB at $20 \mathrm{mM}$ but only achieved about $50 \%$ inhibition from fusobacterium over the target range. SP had no significant effect on sulphide production from either bacterium.

Conclusion: In pure bacterial cultures SAS is more effective than ASA at inhibiting sulphide production from $\mathrm{SO}_{4}$ and sulphur amino acids.

1. Pitcher MCL, Cummings JH. Gut 1996;39:1-4.

2. Pitcher MCL, Beatty ER, Cummings JH. Gut 2000;46:64-72.

3. Roediger WEW, Duncan A. Med Sci Res 1996;24:27-9.

\section{PLATELET ACTIVATION MAY INITIATE LEUCOCYTE-PLATELET AGGREGATION IN INFLAMMATORY BOWEL DISEASE}

U. Azam ${ }^{1}$, P.M. Irving 2 , L. Webb ${ }^{1}$, F.L. Langmead ${ }^{2}$, M.G. Macey ${ }^{1}$, D.S. Rampton ${ }^{2}$. Depts of Haematology $y^{1}$ and Adult and Paediatric Gastroenterology, St Bartholomews E Royal London School of Medicine, London, UK

Background: We have recently shown that the formation of leucocyte-platelet aggregates is increased in the peripheral blood of patients with IBD (Irving, UEGW 2000). Platelets are known to have proinflammatory as well as thrombotic effects and their activation is increased in IBD (Collins, Gastroenterology 1994;106:840-5).

Aims: To assess whether platelet and/or leucocyte activation are correlated with, and might therefore induce formation of leucocyteplatelet aggregates in IBD.
Methods: 56 patients with IBD (29 Crohn's disease, 27 ulcerative colitis) and 19 healthy controls had venous blood drawn into EDTA and CTAD (citrate, theophylline, dipyridamole and adenosine). Samples were immediately mixed and then analysed by flow cytometry for $\mathrm{P}$-selectin (CD62P-for platelet activation), L-selectin (CD62L-for neutrophil activation) and CD45/CD42a (leucocyte-platelet aggregates). Platelet activation was also assessed by analysis of mean platelet mass, an inverse composite measure of platelet degranulation and volume, using an ADVIA Haematology System (Bayer).

Results: We confirmed that leucocyte-platelet aggregation was increased in IBD (median 4.3 (range 1.2-17.3)) compared with controls $(3.3(1.5-7.4), \mathrm{p}<0.05)$. The mean platelet mass was lower in IBD $(1.9(1.6-2.2))$ than in controls $(2.0(1.7-2.3), \mathrm{p}<0.05)$, but activation of platelets as measured by CD62P and of leucocytes (CD62L) were similar in the two groups. Platelet (CD62P), but not leucocyte (CD62L), activation correlated positively with leucocyteplatelet aggregates in IBD $(\mathrm{R}=+0.44, \mathrm{P}<0.01)$.

Conclusions: Leucocyte-platelet aggregation is increased in patients with IBD, and the correlation with platelet activation measured by P-selectin, supports the hypothesis that platelets may contribute to the pathogenesis of the disease by aggregating with circulating neutrophils. The formation of aggregates does not appear to be related to the expression of CD62L on neutrophils.

\section{PERTURBATION OF CLASSICAL CADHERINS IN THE LYMPHOID ASSOCIATED EPITHELIUM; FURTHER INSIGHT INTO THE PATHOGENESIS OF EARLY CROHN'S LESIONS}

D.S.A. Sanders ${ }^{1}$, R.K. Hejmadi ${ }^{1}$, R. Hardy ${ }^{2}$, R. Ransford ${ }^{2}$, J.A. Eksteen ${ }^{2}$, J.A. Jankowski ${ }^{2}$. Depts of ${ }^{1}$ Cellular Pathology and ${ }^{2}$ Medicine, University of Birmingham, UK

Background: The pathogenesis of early Crohn's lesions is poorly understood but probably involves focal alteration of the integrity of the mucosal epithelium with a host inflammatory response to gut luminal antigens. Histologically early pre-ulcerating and aphthoid lesions are often characterised by mucosal lymphoid aggregates. Cadherins have a major adhesive role in maintenance of mucosal integrity and their expression may be altered by inflammatory cytokines.

Aims: We aimed to investigate a putative link between inflammation and epithelial cadherin expression, which may give further insight into the pathogenesis of early lesions in Crohn's disease.

Methods: Endoscopic and surgical resection material was collected from patients with proven Crohn's disease. Examples of preulcerating lesions, early/aphthoid ulcers and non-involved bowel were serially sectioned and stained by routine immunohistochemistry for $\mathrm{E}$ - and $\mathrm{P}$-cadherin (E- and $\mathrm{P}$-cad), $\beta$ - and $\gamma$ catenin, the proliferation marker Ki-67 (MIB-1) and lymphocyte markers CD 20 and CD3.

Results: Membranous upregulation of P-cad, co-expression with E-cad, and increased mucosal proliferation was seen exclusively in crypt and surface epithelium immediately adjacent to lymphoid aggregates and reactive follicles in pre-ulcerating Crohn's lesions $(8 / 10)$, adjacent to lymphoid follicles in non-involved bowel $(5 / 10)$, and in crypts adjacent to aphthoid ulcers (10/10). No alteration in catenin expression was noted.

Discussion: Upregulation of P-cad and co-expression with E-cad is a phenotype associated with cell proliferation, migration, repair and neoplasia in the GI tract. Preliminary experimental data suggests cadherin expression may be influenced by inflammatory cytokines such as $\mathrm{TNF} \alpha$. Our current data shows that perturbation of the main epithelial adhesion molecules, the cadherins, is intimately associated with patchy focal accumulation and activation of lymphocytes in Crohn's disease, which may influence mucosal permeability and hence integrity, initiating patchy superficial aphthoid ulceration.

\section{A DISTINCT PROFILE OF SOLUBLE SELECTIN DURING ACTIVE AND INACTIVE PHASES OF INFLAMMATORY BOWEL DISEASE (IBD)}

G.A. Paspatis ${ }^{1}$, A. Sfyridaki ${ }^{2}$, K. Triantafyllou ${ }^{3}$, K. Patikos ${ }^{3}$, M. Tzouvala ${ }^{3}$, N. Papanikolaou ${ }^{1}$, D.G. Karamanolis ${ }^{3} .{ }^{1}$ Dept of Gastroenterology and ${ }^{2}$ Blood Bank, Benizelion General Hospital, Heraklion, Crete; ${ }^{3}$ Dept of Gastroenterology, Tzanion General Hospital, Piraeus, Greece

Introduction: Data concerning selectin measurements in the serum of patients with IBD and their correlation with disease activity is limited and somewhat contradictory. 